\title{
Outcome of Intramedullary Stainless steel Rush pins for the treatment of Pediatric diaphyseal forearm bone fracture
}

\author{
Poojan Kumar Rokaya, Mangal Rawal, Javed Ahmad Khan \\ Department of Orthopedics and Trauma Surgery, Karnali Academy of Health Sciences, Jumla, Nepal
}

\author{
Correspondence \\ Dr. Poojan Kumar Rokaya, \\ Department of Orthopedics and \\ Trauma Surgery, \\ Karnali Academy of Health \\ Sciences, Jumla, Nepal \\ Email: \\ pkr2039@gmail.com
}

DOI: http://dx.doi.org/10.3126/ jemsn.v12i2.15458

Article received: March $23^{\text {rd }} 2016$ Article accepted: June $20^{\text {th }} 2016$

\begin{abstract}
Background \& Objectives: Pediatric forearm bone fractures are common orthopedic injuries. Generally, these fractures can be successfully managed with closed reduction and casting however operative fixation may be required. Currently, the most common operative interventions are open reduction with plate fixation versus closed or open reduction with intramedullary fixation. Intramedullary fixation materials include Steinmann pins, Kirschner-wires, Rush pins, and elastic titanium nails. To demonstrate the outcome of Intramedullary Stainless steel Rush pins for the treatment of Pediatric diaphyseal forearm bone fracture. Materials \& Methods: This study included thirty children with diaphyseal forearm bone fracture treated with intramedullary stainless steel rush pin. Patient's age, sex, side, mode of injury, fracture type, fixation indication and method, time of clinical and radiological union, complication rate and final range of motion were evaluated at subsequent follow up-. Clinical evaluation was done as per Price's criteria. Results: Among 30 patients there were 22 boys $(73.3 \%)$ and 8 girls $(26.6 \%)$ with a mean age of 11.8 years (Range, 5 to 14 years). Twenty $(66.6 \%)$ patients had right forearm fracture, $10(33.3 \%)$ patients had left forearm fracture. Union was obtained in a mean of $6.5 \pm 1.0$ weeks (range 6 to 9 weeks). According to the criteria of Price et al. an excellent result was achieved in 25 patients $(83.3 \%)$ and a good result in five patients $(16.6 \%)$. Out of total 30 patients six $(20 \%)$ had minor complications. Conclusion: Fixation with intramedullary stainless steel rush pin produces good to excellent results in diaphyseal forearm bone fractures in children. Based on our experience, rush pins are simple, safe, easily available and affordable to most of the patients in developing countries.
\end{abstract}

Key words: Children; Diaphyseal forearm bone; Rush pin

Citation: Rokaya PK, Rawal M, Khan JA. Outcome of Intramedullary Stainless steel Rush pins for the treatment of Pediatric diaphyseal forearm bone fracture. JCMS Nepal. 2016;12(2):50-4.

\begin{tabular}{|c|c|}
\hline $\begin{array}{l}\text { INTRODUCTION } \\
\text { Pediatric fractures present significant challenges to } \\
\text { the orthopedic community. Diaphyseal fractures of } \\
\text { the radius and ulna, commonly referred to as both } \\
\text { bone forearm fractures, are the third most common } \\
\text { fracture in the pediatric population and account for } \\
13 \text { to } 40 \% \text { of all pediatric fractures. } \\
\text { Unlike forearm bone fractures in adults, which are } \\
\text { generally treated by open reduction and } \\
\text { osteosynthesis with plate and screw fixation, } 90 \% \\
\text { of pediatric forearm fractures are successfully } \\
\text { treated conservatively by closed reduction and } \\
\text { casting. The remaining } 10 \% \text { are irreducible or } \\
\text { unstable fractures of which treatment methods } \\
\text { include closed manipulation and casting under } \\
\text { general anesthesia, fixation with pins and plaster, }\end{array}$ & $\begin{array}{l}\text { closed or open reduction with a mini incision and } \\
\text { intramedullary nailing, open reduction and } \\
\text { osteosynthesis with plate and screw fixation, and } \\
\text { external fixators. }{ }^{2} \text { Recently fracture fixation with } \\
\text { intramedullary nails has gained popularity due to } \\
\text { several advantages such as maintenance of } \\
\text { reduction, minimally invasive, relatively easy } \\
\text { application, protection of bone alignment and } \\
\text { retention of biologic factors at the fracture site. }{ }^{3} \\
\text { Titanium elastic nails are increasingly used for } \\
\text { intramedullary nailing because of their elastic } \\
\text { properties which allow for improved insertion and } \\
\text { rotation while still providing adequate fracture } \\
\text { stabilization. }{ }^{4} \text { However titanium elastic nails are } \\
\text { expensive for most of the patients of low } \\
\text { socioeconomic status of developing countries on }\end{array}$ \\
\hline
\end{tabular}


contrary to that stainless steel Rush pins are cheaper and easily available.

This study was carried out to evaluate the clinical and radiological outcome of pediatric diaphyseal forearm bone fractures treated with intramedullary stainless steel Rush pins.

\section{MATERIALS AND METHODS}

This study was conducted among the children who presented with forearm bone fractures at Department of Orthopedics and Trauma Surgery, KAHS Jumla from June 2013 to December 2015 after ethical approval from the Institutional Review Board. Children of five to 14 years of age with displaced and grossly rotated diaphyseal forearm bone fractures, failed closed manipulation, patients with adequate follow-up and complete medical records were included in this study after taking an informed written consent. No extra financial burden was given to the patients. Patients with isolated forearm bone fracture, compound fractures, fractures with neurovascular injury, pathological fractures, Galeazzi or Monteggia fracturedislocations, proximal and distal third forearm bone fractures were excluded from the study.

Patients' age, sex, side, mode of injury, fracture type, fixation indication and method, time of clinical and radiological union, complication rate and final range of motion were evaluated at subsequent follow up. Angulations in one of the two planes greater than 20 degrees in children younger than 10 years, and angulations greater than 10 degrees in children older than 10 years were defined as unacceptable and treated surgically., Rotational deformities were also regarded as an indication for surgical treatment.

Fracture union was defined as the radiological appearance of bridging callus at the fracture site on both the planes together with a pain-free fracture site.

Complications requiring a subsequent intervention or the use of anesthesia that might affect long term functional outcome, iatrogenic problems related to technique or implant use and unacceptable reduction were considered as major complications, while those that were not important enough to affect long-term prognosis or functional results were accepted as minor complication. ${ }^{5}$

Clinical outcomes were evaluated as per Price criteria ${ }^{7}$ according to which absence of complaints with strenuous activity or loss of forearm rotation of less than 10 degrees or both showed an excellent

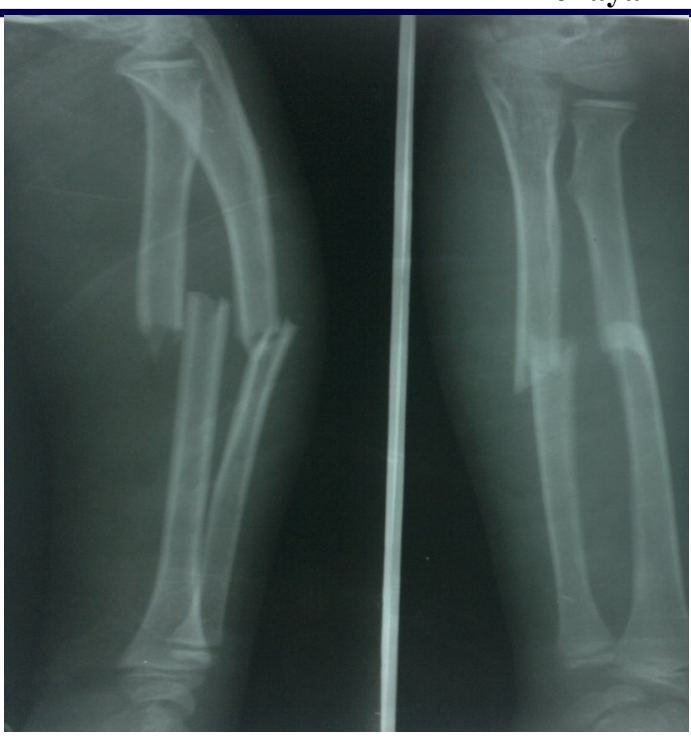

Fig 1: Diaphyseal right forearm bone fracture of $10 \mathrm{yrs} / \mathrm{m}$

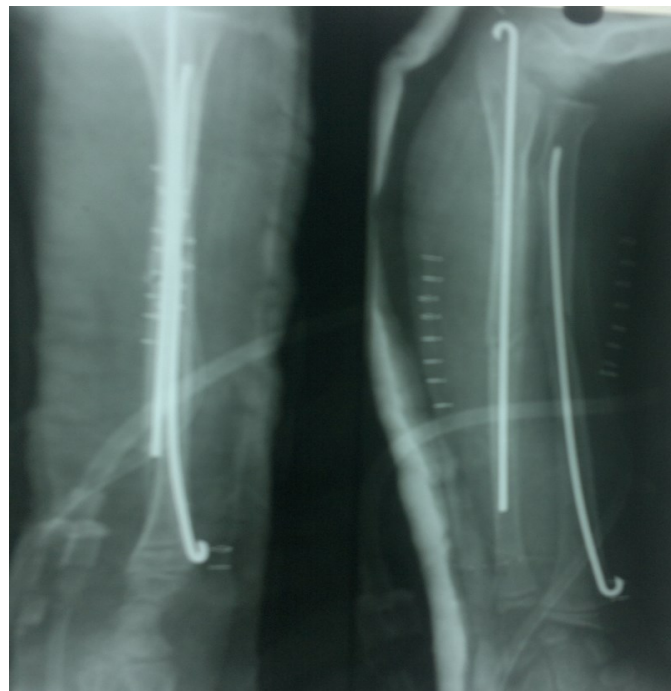

Fig 2: Open reduction by mini incision and intramedullary fixation with Stainless steel rush pins on third day of admission

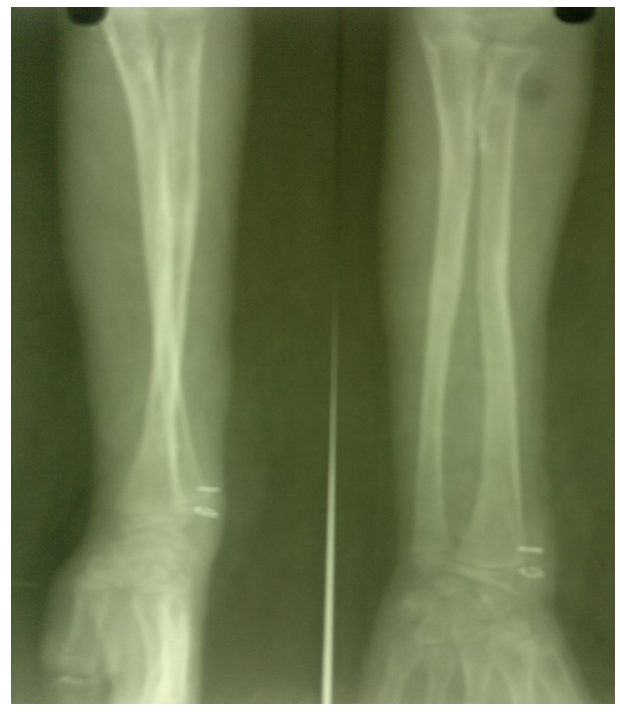

Fig 3: Implant removal after 8 months of fixation 
result; the presence of mild complaints with strenuous activity or a rotational loss of 11 to 30 degrees showed a good result; subjective complaints during daily activities or rotational loss of 31 to 90 degrees showed a fair result. All other conditions were considered to be a poor outcome. Data analysis was done using Statistical Package for Social Sciences (SPSS) 17.0 version.

\section{Surgical technique}

A pneumatic tourniquet was used in all patients. Under appropriate anesthesia using image intensifier radial nailing was done retrogradely. Rush pin was advanced through a dorsal entry point two to three $\mathrm{cm}$ proximal to the distal radial epiphyses. Diameter of pin used varied from two to three $\mathrm{mm}$ depending upon the diameter of medullary cavity at the level of isthmus. The nail length was measured from distal to the proximal growth plate under image intensifier. The tip of radial pin was bent to about 40 degrees to allow easy passage of the nail through the medullary canal and also to help in fracture reduction. The rest of the radial pin was bent to about 20 degrees to match the radial bow and to ensure restoration of the interosseous space. Optimal care was taken not to injure extensor tendons and superficial radial nerve. Ulnar pin was inserted antegradely through the olecranon. The ulnar pin only requires minimal prebending of about 10 degrees because the bone is almost straight. This prebending helps in three point fixation of the nail inside the ulnar bone canal and thus theoretically provides better fracture stability. Rush pins were buried under the skin in all the cases.

Post operatively, a long arm posterior splint was applied in all cases for six weeks. Active finger movements were encouraged after operation. Active and active assisted intermittent flexion and extension of wrist and elbow was started from second postoperative day. Supination and pronation of forearm was allowed after removal of splint at six weeks. Patients were followed up at two weeks, six weeks, three months, and six month time for radiological and functional evaluation.

\section{RESULTS}

Thirty patients met our criteria and were included in this study. There were 22 boys (73.3\%) and eight girls $(26.6 \%)$ with a mean age of 11.8 years (Range, five to14 years). Twenty (66.6\%) patients had right forearm fracture whereas $10(33.3 \%)$ patients sustained injury to left side.
The mechanism of injury in ten patients was a simple fall onto the outstretched hand, nine falls from a height, five sports related injuries, three had bicycle accidents and three patients were of physical assault. The mean time from injury to surgery was five days (range two to eight days). Closed reduction and nailing with Rush pin was successful in 19 cases whereas 11 patients required mini open reduction due to soft tissue interposition. Union was obtained in a mean of $6.5 \pm 1.0$ weeks (range six to nine weeks). According to the criteria of Price et al. ${ }^{7}$ an excellent result was achieved in 25 patients $(83.3 \%)$ and a good result was achieved in five patients $(16.6 \%)$. There were no cases in fair group.

Out of total 30 patients six $(20 \%)$ had minor complications. Two patient developed olecranon bursitis due to ulnar pin irritation, which resolved after the removal of the pin. Two patients had superficial skin infections at the entry point which were treated with appropriate wound care and antibiotics. There was retrograde migration of ulnar pin requiring early removal in one patient. One patient had delayed union of the ulna which finally united at eight months after operation without any further intervention. None of the patients had complications such as limb-length discrepancy affecting the upper extremity functions, epiphyseal damage, angular or rotational deformity, synostosis or limited elbow or forearm range of motion. No cases of nonunion or malunion were reported.

The implants were removed under appropriate anesthesia at an average of six months following primary fixation. The mean follow-up period was 12 months (range six to 30 months)

\section{DISCUSSION}

Historically, the majority of pediatric diaphyseal forearm bone fractures have been treated with nonoperative management relying on closed reduction and casting. This treatment is associated with loss of reduction and poor functional results in five to seven percent of the patients. ${ }^{8}$ Recently there has been a trend towards increased surgical management of these fractures in an effort to improve clinical outcomes. The clinical results of pediatric forearm fractures mainly rely on residual angulations at the fracture site, the presence of a rotational deformity, remodeling potential of the bone, the age of the patient, and the location of the fracture. ${ }^{9}$

It has been reported that middle third fractures 
cause more functional limitations compared to distal third diaphyseal forearm fractures. ${ }^{5,9,10}$ A cadaver study by Tarr RR et al. ${ }^{10}$ showed that supination losses were much more obvious than pronation losses in middle third forearm fractures. Thus, angulations greater than 20 degrees and 10 degrees were treated surgically in children younger and older than 10 years, respectively. ${ }^{2}$

Shoemaker SD et al. ${ }^{11}$ suggested that the ideal mode of fixation of pediatric forearm fractures should maintain alignment, be minimally invasive and inexpensive, and carry an acceptable risk profile. Compared with open reduction and osteosynthesis with plate-screw fixation, intramedullary nailing meets these criteria.

The main advantages of intramedullary nailing include maintenance of reduction, provision of an inexpensive, minimally invasive, relatively easy application, protection of bone alignment by three point contact, acceleration of bridging callus formation through micro movements at the fracture site, and thus contribution to rapid bony healing. ${ }^{12}$

Intramedullary fixation materials include Steinmann pins, Kirschner-wires, Rush pins, and elastic titanium nails. In the clinical setting, titanium is being used more often than stainless steel because of the elastic properties which allow for improved insertion and rotation but it may be expensive and not easily available in many hospitals of developing countries.

Outcome of treatment with intramedullary stainless steel rush pin in diaphyseal forearm bone fracture was excellent in $25(83.3 \%$ ) patients and good in five $(16.6 \%)$ patients in this study which is similar to study done by Yalcinkaya et $\mathrm{al}^{2}$, Shoemaker SD et $\mathrm{al}^{11}$ and Flynn JM et $\mathrm{al}^{13}$ (table1). Stainless steel rush pin is a reasonable option and it can be used like titanium elastic nails in peripheral orthopedic setup of developing countries for managing pediatric diaphyseal forearm bone fractures. Though insertion of Rush pin may be difficult as it is less malleable it offers various potenti--al benefits likes cosmetics, easy removal after treatment and decreased chances of neurovascular injuries. ${ }^{14}$

Close reduction or open reduction before intramedullary nailing yield similar functional results, with similar complication profile in pediatric diaphyseal forearm bone fracture. Luhmann et al. ${ }^{15}$ advocated that open reduction with a small incision would cause much less trauma to tissues than that caused by multiple reduction maneuvers. In this study eleven patients had undergone mini op-en reduction due to soft tissue interposition and their outcome was similar to patients treated with closed reduction and intramedullary nailing.

In our study, six $(20 \%)$ patients developed minor complications most of which resolved after implant removal. Cullen at al. ${ }^{16}$ reported complications as high as $50 \%$ following intramedullary fixation of pediatric forearm bone fractures. Yalcinkaya et al. ${ }^{2}$ reported complications rate ranged from four to $38 \%$ in patients treated with intramedullary nailing. The cause of these complications is difficult to determine, it is due to the surgeon's inexperience with the technique or the surgery itself, and some consider the second procedure to remove the implants to be a disadvantage of intramedullary nailing. ${ }^{17}$

Sample size, study duration and non-comparative nature of the present study are the limitations of our study. However this study will serve as a baseline data in future in demonstrating the differences between the results of elastic nails versus rush pin or intramedullary nailing versus plate fixation or closed versus mini open intramedullary nailing for pediatric diaphyseal forearm bone fractures.

\section{CONCLUSION}

Intramedullary Stainless steel Rush pin is a simple, safe and cost effective method in the treatment of pediatric diaphyseal forearm bone fracture. They are easily available and affordable to most of the patients in developing countries with good to excellent functional and radiological outcome. Complications are minor and most of them resolve with implant removal.

\section{REFERENCES}

1. Vopat ML, Kane PM, Christino MA, Truntzer J, McClure P, Katarincic J, Vopat BG. Orthop Rev (Pavia). 2014 Jun 24;6(2):5325. DOI: 10.4081/or.2014.5325. PMID: 25002932

2. Yalcinkaya M, Dogan A, Ozkaya V, Sokucu S, Uzumcugil O, Kabukcuoglu Y. Clinical results of intramedullary nailing following closed or mini open reduction in pediatric unstable diaphyseal forearm fractures. Acta Orthop Traumatol Turc 2010; 44 (1): 7-13. DOI: 10.3944/AOTT.2010.2260. PMID: 20513985.

3. Lee S, Nicol RO, Stott NS. Intramedullary fixation for pediatric unstable forearm fractures. Clin Orthop Relat Res 2002;(402):245-50. DOI: 10.1097/00003086200209000-00024. PMID: 12218490

4. Lascombes P, Haumont T, Journeau P. Use and abuse of flexible intramedullary nailing in children and adolescents. J Pediatr Orthop 2006;26:827-34. DOI: 10.1097/01.bpo.0000235397.64783.d6. PMID: 17065959. 
5. Özkaya U, Parmaksızoğlu AS, Kabukçuoğlu Y, Yeniocak S, Sökücü S. Surgical management of unstable both-bone fore arm fractures in children. [Article in Turkish] Acta Orthop Traumatol Turc 2008;42:188-92. DOI: 10.3944/ AOTT.2008.188. PMID: 18716434.

6. Küçükkaya M, Kabukçuoğlu Y, Tezer M, Eren T, Kuzgun Ü. The application of open intramedullary fixation in the treatment of pediatric radial and ulnar shaft fractures. J Orthop Trauma 2002;16:340-4. DOI: 10.1097/00005131-200205000-00008. PMID: 11972077.

7. Price CT, Scott DS, Kurzner ME, Flynn JC. Malunited forearm fractures in children. J Pediatr Orthop 1990;10:705-12. DOI: 10.1097/01241398-19901100000001. PMID: 2250053.

8. Richter D, Ostermann PA, Ekkernkamp A, Muhr G, Hahn MP. Elastic intramedullary nailing: a minimally invasive concept in the treatment of unstable forearm fractures in children. J Pediatr Orthop 1998;18:457-61. DOI: 10.1097/00004694-199807000-00010 PMID: 9661852.

9. Younger AS, Tredwell SJ, Mackenzie WG, Orr JD, King PM, Tennant W. Accurate prediction of outcome after pediatric forearm fracture. J Pediatr Orthop 1994;14:2006. DOI: 10.1097/01241398-199403000-00013. PMID: 8188834.

10. Tarr RR, Garfinkel AI, Sarmiento A. The effects of angular and rotational deformities of both bones of the forearm. An in vitro study. J Bone Joint Surg [Am] 1984;66:65-70. PMID: 6690445.

11. Shoemaker SD, Comstock CP, Mubarak SJ, Wenger DR, Chambers HG. Intramedullary Kirschner wire fixation of open or unstable forearm fractures in children. J Pediatr Orthop 1999;19:329-37. DOI: 10.1097/00004694199905000-00009. PMID: 10344315.

12. Yung PS, Lam CY, Ng BK, Lam TP, Cheng JC. Percutaneous transphyseal intramedullary Kirschner wire pinning: a safe and effective procedure for treatment of displaced diaphyseal forearm fracture in children. $\mathrm{J}$ Pediatr Orthop 2004;24:7-12. DOI: 10.1097/01241398200401000-00002. PMID: 14676526.

13. Fynn JM, Jones KJ,Garner MR, Goebel J. Eleven years experience in operative management of pediatric forearm fracture. J J Pediatr orthop 2010; 30: 313- 19. DOI: 10.1097/BPO.0b013e3181d98f2c. PMID: 20502228.

14. Fernandez FF, Egenolf M, Cansten C, Holz F, Schneider $\mathrm{S}$, Wentzensen A. Unstable diaphyseal fracture of Both Bones of the forearm in children. Plate fixation Vs Intramedullary nailing. Injury 2005; 36 (10): 1210-6. DOI: $10.1016 /$ j.injury.2005.03.004. PMID: 16122742 .

15. Luhmann SJ, Gordon JE, Schoenecker PL. Intramedullary fixation of unstable both-bone forearm fractures in children. J Pediatr Orthop 1998;18:451-6. DOI: 10.1097/00004694-199801000-00017. PMID: 9661851.

16. Cullen MC, Roy DR, Giza E, Crawford AH. Complications of intramedullary fixation of pediatric forearm fractures. J Pediatr Orthop 1998; 18:14-21. DOI: 10.1097/01241398-199801000-00004. PMID: 9449095.

17. Shah AS, Lesniak BP, Wolter TD, Caird MS, Farley FA, Vander Have KL. Stabilization of adolescent bothbone forearm fractures: a comparison of intramedullary nailing versus open reduction and internal fixation. J Orthop Trauma 2010;24:440-7. DOI: 10.1097/ BOT.0b013e3181ca343b. PMID: 20577077. 